\title{
Jakarta Readiness in Facing Clean Energy Public Electric Vehicle Charging Stations Need Analysis
}

\author{
Toni Prasetyo ${ }^{1}$, Muhamad Rizky² ${ }^{2}$ Robertus Irwan Putrantomo ${ }^{3}$, Tiara Yasinta ${ }^{4}$ \\ \{toni.pras@gmail.com¹, baros2002@outlook.com², tuschemeng2012@gmail.com³\} \\ School of Environmental Science, University of Indonesia, Salemba Raya street No. 4, Jakarta Pusat, \\ Indonesia
}

\begin{abstract}
Indonesia is one of countries committed to reducing greenhouse gas emissions. To support this commitment, Indonesia enact regulation regarding Acceleration of the Battery-Based Electric Motor Vehicle Program for road transportation (Perpres RI No. 55/2019). Since the enactment of these regulations, developments in the demand for electric vehicles (EV) have increased. The main impact of the transition is the construction of electricity charging infrastructure for EV. Currently Jakarta already have 721 public EV charging station to support EV population in Jakarta and this study will analyse if the current number and area that have been determined is already sufficient. The study will use population-based equation from literature review to compare ideal number of public EV charging station with actual number that have been installed. The result is number of existing installed public EV charging station in Jakarta (721 ea) is still sufficient to support EV development program in Jakarta, however from physical observation it is necessary to reassess current area that had been installed for public EV charging station to be comply with minimum requirement of public EV charging station. Future work will require assessment of all installed public EV charging station and efficiency of the charging station in term of location and ease of usage.
\end{abstract}

Keywords: electric vehicle; charging station; analysis

\section{Introduction}

Population and transportation needs growth in Indonesia continue to increase from year to year. In line with the statement of BPS [1], the projected population growth in Indonesia shows that the population of Indonesia over the next twenty-five years continues to increase, from 238.5 million in 2010 to 305.6 million in 2035 . Increasing population is directly proportional with increased transportation needs. Demand for transportation needs has increased significantly from year to year over the past 10 years. According to BPPT Data [2], the number of vehicles increased from 18.98 million units in 2000 to 77.13 million units in 2010 or grew by an average of $15.1 \%$ per year. At present the largest share is the use of motorbikes which reaches $79 \%$ of the total number of motor vehicles [2]. The increase in vehicle demand has an impact on increasing the demand for fuel energy. The increase demand for fuel energy will increase the concentration of greenhouse gas emissions. The use of fuel derived from petroleum until now has not been substituted with materials or energy sources of other types [3], so it is predicted to decrease so that energy for transportation requires innovative steps into the future, one of the main alternatives is to use electric vehicle (EV). 
Indonesia is one of the countries committed to reducing greenhouse gas emissions [4]. To support this commitment, President Joko Widodo on August 8, 2019 established a policy regarding Presidential Regulation of the Republic of Indonesia Number 55 Year 2019 concerning the Acceleration of the Battery-Based Electric Vehicle for road transportation. Electric vehicles have an obvious advantage in energy utilization rate and emission rate. In general, EVs produce fewer emissions that contribute to smog and climate change than conventional vehicles. Because most emissions are lower for electricity generation than burning gasoline or diesel [5]. Since the enactment of these regulations, developments in the demand for electric vehicles have increased. With the electric vehicle market expanding, the investment opportunities for incoming electric vehicles are even greater [6].

Electric Vehicle will always be related to electricity needs [7]. In addition the Electrical Vehicle will need a system to charge electricity for its operation, the Electrical Vehicle charger. Because if it is not refilled or charging, the Electrical Vehicle becomes useless. Charging or recharging power sources which are generally in the form of lithium ion or nickle ion batteries and others are the main things in building an electrical vehicle system.

The transition to the use of fuel vehicles to EV will have implications in urban spatial planning, especially in Jakarta. Jakarta is one of the cities with the largest amount of transportation in Indonesia. However, an increase in the number of vehicles was not followed by adequate urban planning. The main impact of the transition is the construction of electricity charging infrastructure for EV. EV Charger is an electrical device that converts alternating current energy to regulated direct current for replenishing the energy of an energy storage device (i.e. battery) and may also provide energy for operating other vehicle electrical systems [8]. Based on research, in 2010 according to the Jakarta Spatial General Plan the proportion of land use that was openly developed in Jakarta was 87: 13[9]. It shows that Jakarta's current environmental burden has almost exceeded its carrying capacity. This paper aims to analyze the land area and location readiness of EV Charging Station in Jakarta.

Generally, there are 3 categories of charging systems for electric vehicle in Indonesia: conductive, inductive, and battery swap. There are pros and cons for each charging systems. Conductive charging system can be vary in charging time and locations but it requires complex charging infrastructure [10]. Inductive charging system involves no danger of such wiring on conductive charging and can be done in wet, sandy, dusty, or snowy conditions, but the system is still under development [10]. Battery swap charging system has unlimited vehicle mileage with available battery swap stations and $100 \%$ of battery will be fully restored in less than 1 minute, but expenses on monthly battery will possibly be greater than the charging conventional vehicles [10].

Potential consumer of electric vehicles should be identified as its preference will be the basis of public charging stations infrastructure's design. In terms of economic aspect, full-time workers living in small to medium-sized municipalities have the most suitable mobility profiles, therefore they are encouraged to shift towards electric vehicle first [11]. It is found that middleaged, male, and live in multi-person households are more interested towards electric vehicles [11]. Residents of smaller settlements are more likely to be the early adopters, it is because people from large cities typically do not drive enough kilometres per year so that electric vehicle can become cost-effective [11]. In terms of gender, male drivers become the typical early adopters for electric vehicles [12]. Early adopters of electric vehicles also has some other typical characteristics such as they are belong to rather higher end of salaries and have a relatively high level of education [12]. People with college education is $20 \%$ more likely to adopt electric vehicles while people in the middle to high-income groups is $16 \%$ more likely to adopt electric vehicles [13]. 
It is important to identify the motivations and barriers of electric vehicle users. Based on previous research, most of electric vehicle consumers use their car for private purposes [12]. It is also found that $69 \%$ of respondents are very satisfied with their electric vehicles and $29 \%$ are satisfied, but they will consider only use an electric vehicle in the near future [12]. Main reason for people to use an electric vehicles is because of the lower impact caused to the environment, followed by cost-efficiency which refers to the charging cost and other costs such as maintenance [12]. As for the barrier that existed are electric vehicles relatively more expensive rather than the conventional ones. There is also range anxiety caused by limited of driving range compared to conventional ones and lack of strong incentive programs as the barriers to implement transition to electric vehicles [12]. Variety of solutions have been proposed to overcome the barriers, such as separating the selling of battery and electric vehicle itself, since the battery is the most expensive component which makes it much more expensive rather then the conventional ones [14]. Intelligent Transportation System (ITS) also has been developed to reduce range anxiety of consumers towards the electric vehicles. Consumers will be able to monitors the battery's energy status and get a reminder when the battery reaches a lower threshold level, in case of malfunction, ITS will also give a signal [14].

Based on Presidential Regulation No. 55/2019, Indonesia government at least have five programs to accelerate EV development which one of the programs is to support EV charging station installation. EV requires charging station to supply its need for electric energy and also battery to store the energy inside. According to [15], not having enough access to efficient charging station rank third as barrier to EV purchase next to EV price and driving range. It is also important to first raise the environmental awareness of people to allow better penetration of electric vehicles [12].

EV battery capacity varies from 20 to $60 \mathrm{kWh}$ and various charging technology have been developed from single phase AC system with up to $3 \mathrm{~kW}$ charging power that will take about 7 hour to charge $20 \mathrm{kWh}$ battery until current fast charging level that will fully charge the battery in $20-30$ minutes[16]. See

Table 1 for detail of EV charging station type and their standard use.

There are typically three charging station types for EVs, i.e. private charging piles [17], public charging stations [18], and mobilized chargers [19]. In high density cities, development of private charging piles is not achievable due to limited amount of space in owners garage thus it will depend on availability of public charging station to support wide application of EVs [20]

Table 1. Types of EV charging station.

\begin{tabular}{|c|c|c|c|}
\hline Type & $\begin{array}{l}\text { Power } \\
\text { (volt) }\end{array}$ & $\begin{array}{c}\text { Time } \\
\text { (hours) }\end{array}$ & Standard Use \\
\hline AC Level 1 & 120 & $6-10$ & $\begin{array}{l}\text { Staff use during work } \\
\text { day, long term } \\
\text { parking at commuter } \\
\text { lots or vehicles parked } \\
\text { overnight. }\end{array}$ \\
\hline AC Level 2 & $\begin{array}{c}204- \\
240\end{array}$ & $1-3$ & $\begin{array}{l}\text { Commercial use or } \\
\text { work vehicles that are } \\
\text { heavily used and need } \\
\text { a midday charge. }\end{array}$ \\
\hline $\begin{array}{l}\text { DC fast } \\
\text { charger }\end{array}$ & 480 & 0,5 & $\begin{array}{l}\text { Best for highway sites } \\
\text { to enable longer } \\
\text { vehicle trips }\end{array}$ \\
\hline
\end{tabular}


General EV charging station will include power source, parking surface, barrier or mounting option and sign or pavement marking. Majority of workplace and public EV charging station will be located in parking lots with perpendicular parking layout [22]. A minimum width of 9 feet and length of 18 is required per connector [23] or area of $25 \mathrm{~m}^{2}$ is required per connector in EV charging station. Figure 1 describe tipical EV charging station layout.

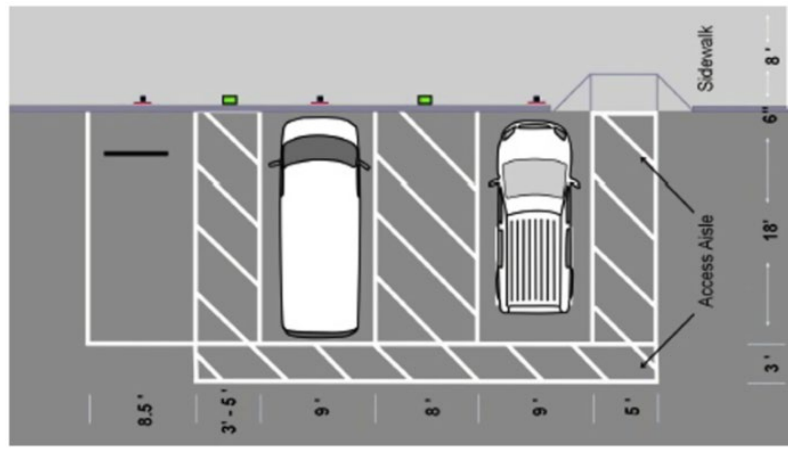

Figure 1. Typical EV charging station layout [23]

Previous studies related with sizing and siting of public EV charging station already abundant in recent publications. For example, [24] that determine optimal EV charging station as a function of parking demand and access cost (walk distances). The study attempts to best satisfy demand for public charging of EVs on the basis of parking duration, land use attributes, and (in the case of individual parking duration) trip chracteristics.

There is a proposal new approach for optimal placing and sizing for EV charging stations [23]. The approach minimizes the total cost of station development and electrification costs and also considers urban roads to find candidate station points and calculate EV energy loss by formulating the problem as Mixed-Integer Non-Linear (MINLP) problem which is finally solved by genetic algorithm (GA).

While another research proposes a novel Geographic Information System (GIS) assisted optimal design method of solar powered charging stations for promoting EV applications in high density cities [20]. By selecting the optimal locations and optimal number of the renewable powered charging stations with the considerations of the existing charging stations and renewable potentials, the proposed method is able to minimize the life cycle cost of the charging stations while satisfying a user defined area coverage ratio. To verify the proposed method, case studies were conducted in a real district of Hong Kong. The results were analysed and compared with other non-optimal options in terms of life cycle cost and district coverage ratio.

Planning of infrastructure to support electric vehicles is an important matter. Preferences of user need to be addressed. Choosing a new vehicle involves factors such as reliability, ahead of fuel economy, price, and safety [25]. Placement of public charging stations also play an important role towards the successful transition of fossil fuel vehicles to electric ones. Places like grocery stores, work, mall, near home, and near freeway are much preferred rather than gym or school [25]. Willingness to pay also vary for every possible scenario, for example people will pay more for level 2 grocery store access rather than quick charging near freeway [25]. In case of parity between gasoline and electricity refuel cost, people would be willing to wait 8 minutes longer to recharge [25].

Number of quick charging stations also will affect the trend of population growth [26]. Tradeoffs between battery capacity, charging infrastructure coverage, and charging power 
should be addressed since development of charging stations infrastructures are not an easy matter. Combination of battery capacity $112,8 \mathrm{kWh}$ with home charging at $3,68 \mathrm{~kW}$ will give result of $91 \%$ portion of mileage that is electrically drivable, the same result given from the combination of $37,6 \mathrm{kWh}$ battery capacity and public charging locations with $50 \mathrm{~kW}$ at $40 \%$ of the parking locations and with combination of battery capacity $56.4 \mathrm{kWh}$ and public charging locations with $120 \mathrm{~kW}$ at $10 \%$ of the parking locations available [27]. Combination between all of those factors are important towards the sustainability of electric vehicle usage in Indonesia.

There are some factors that influence the overal assessment of public charging infrastructure: basic charge, density of charging station, and charging duration [28]. Charging duration has the most leverage towards the assessment of public charging infrastructure [28]. Willingness to pay of potential consumer still relatively low, despite the very well proposed equipped public charging stations, therefore additional information such as comparison of refueling cost between fuel and electric vehicles should be clearly provided [28].

Presidential Regulation Number 55/2019 already set the target area for public charging stations in Indonesia: fuel stations, gas stations, government offices, mall, and public parking areas on the roadside. Government will also give incentives to stakeholders that helps the acceleration of battery electric vehicles (BEV) program such as manufactures, research and development, provider of public charging stations, battery waste management, and consumers of electric vehicles. Based on the regulation, public charging stations should be reachable, provide special parking areas, and will not disrupt traffic in nearby areas.

The number of EV public charging station plays important role on electric vehicle development especially in urban city. Even Jakarta the number of electric vehicles is still relatively small, which based on data from Korlantas Polri that the number of electric vehicles in Jakarta about 1.150 units in 2019. But the government already start to build charging Station on many points in Jakarta, the Government Electric Company (PLN) already invest and installed about 721 charging unit in Jakarta area only [29], this is because the readiness of the infrastructure needs to be done first to support and encourage people to shifting to electric vehicles. It is important to study about three categories: charging demand, stations coverage, and target market, to finally be able to find the optimal locations for public charging stations as per figure below:

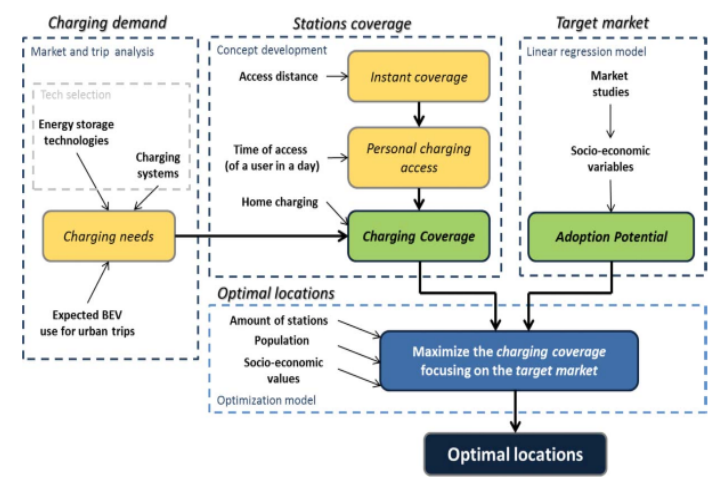

Figure 2. Station location approach [13]

The study in this paper will focus on needs analysis of current EV charging station installation in Jakarta city as a case of study. The adequacy of exisiting EV public charging station will be determined using population based equation as used in [26]. Physical observation of existing EV public charging station in Jakarta also conducted in this study to get 
understanding of current EV public charging station installation layout compared with common typical layout based on literature.

The rest of this paper is arranged as follows. Section Methods present details of population based equation that is used to estimate optimal amount of EV public charging station. Section Result and Discussion present adequacy evaluation of existing EV public charging station compared to optimal aamount from the equation. Result of physical observation of EV public charging station also presented in this section. Conclusive remarks are given in Conclusion section.

\section{Method}

To estimate the ideal number of charging station in Jakarta, in this study we will use population based equation [26] as below:

$$
N \text { station } \geq \frac{A \times \rho_{\text {density }} \times \rho_{B E V}}{\operatorname{sh} \times n c p \times n s t}
$$

where:

A : size of an area (sq.km²);

$\rho_{\text {density }} \quad:$ population density $\left(\mathrm{man} / \mathrm{km}^{2}\right)$;

$\rho_{\mathrm{BEV}} \quad$ : proportion of the EV owners per the number of population in an area (in this case is Jakarta);

ncp : number of charging sockets in a charging station;

nst : number of services per hour of the charging station per hour of charging time in EVs are equal to $n s t=\frac{1 h r}{t_{e v}}$; and

sh : number of services per hour of the charging station in a day.

From the equation we could estimate that the number of EV public charging station in Jakarta whether it is ideal or not in term of numbers.

\section{Result And Discussion}

The basic thinking of the calculation is we could determine the the current number of charging station whether the number is ideal or not in term of the number of electric vehicles which already operated in Jakarta area. By this method we also determine the maximum ideal of number of vehicles that could be cover by the current amount of charging station. This calculation also could give the currenct and future condition of relation between electric vehicles vs charging station in order to give clear insight for the government or private sector that related to electric vehicle.

Given the equation (1), we could generate the result based on the equation with the current condition value 
Table 2. EV public charging station calculation

\begin{tabular}{|clc|}
\hline Parameter & \multicolumn{1}{c}{ Definition } & $\begin{array}{c}\text { Current } \\
\text { Value }\end{array}$ \\
\hline$A$ & Size on an Area & 662,3 \\
$p_{\text {density }}$ & Population density & 15.663 \\
$p_{\text {BEV }}$ & Proportion EV & $0,01 \%$ \\
& Owner/population & 0,3 \\
$n s t$ & Number of services per hour & 3 \\
Tev & Charging time of each EV & 6 \\
sh & number of services per station & 6 \\
$n c p$ & number of sockets & $\mathbf{7 2 1}$ \\
\hline Nfstation & Charging Station number & \\
\hline
\end{tabular}

$$
721 \geq \frac{662,3 \times 15.663 \times 0,01}{6 \times 6 \times 0,3}
$$

By this result we could determine that current condition the number of charging station is still in ideal number. The number of charging station in term of quantity is still satisfied the necessity of electric vehicle for battery charging. We also could determine by the equation the estimation of maximum number of electric vehicles could be bear by the current amount of charging station.

This formula can also be used to estimate the capacity of electric vehicles can be handled with these number of charging stations. If we input 721 as the charging station number, we will get result 8.652 electric vehicles. This result is approximate of maximum amount of number electrical vehicles in ideal condition.

Concerning amount of area required for EV publc charginf station, from [23] it is estimated that efficient area per charging socket is $25 \mathrm{~m}^{2}$. Therefore for 6 socket charging station, area required will be $150 \mathrm{~m}^{2}$. With 721 unit public charging station in Jakarta, total area required will be $108.150 \mathrm{~m}^{2}$.

However from physical observation as exampled in Figure 3, it is then we see that even though the number of EV public charging station is sufficient for current EV population in Jakarta, total area that have been determined need to be improved to support EV development program in Jakarta

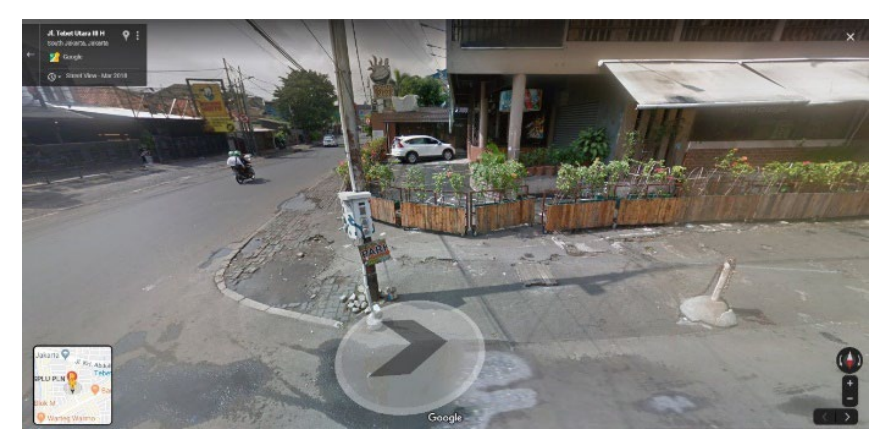

Figure 3. Example of current EV public charging station in Jakarta 
It is stated that the minimum of electric vehicle public charging stations should be approximately $25 \mathrm{~m}^{2}$ and it also should near public building like mall or grocery stores. An example can be seen from the electric vehicles public charging stations in America by Walmart in Figure 4.

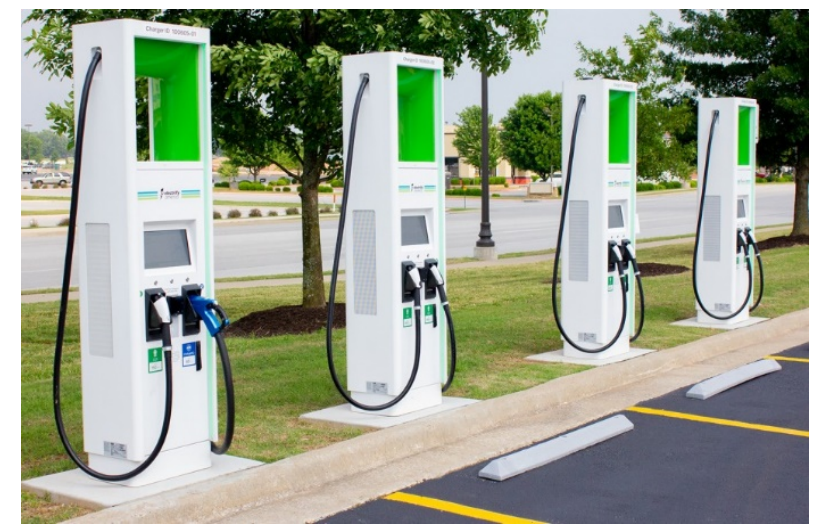

Figure 4 Example of EV public charging station in America [30]

It can be compared from both figures that while Indonesia might have reach sufficient public charging stations in term of number, but the choice of locations and facilities still far from ideal.

\section{Conclusion}

Currently Jakarta has 721 public EV charging station to support EV development program. The number of current public EV charging station (721 ea) is sufficient for current EV population in Jakarta. The total area required for the 721 public EV charging station will be $108.150 \mathrm{~m}^{2}$ ideally from literature review. However compared with existing public EV charging station, it is required further assessment so that area that already been installed will comply with ideal area for public EV charging station. Future work will require assessment of all installed public EV charging station and efficiency of the charging station in term of location

\section{References}

[1] BPS, Indonesia Population Projection. 2013.

[2] BPPT, "Outlook Energi Indonesia 2016," 2016.

[3] E. Liun, "DAMPAK PERALIHAN MASSAL TRANSPORTASI JALAN RAYA KE MOBIL LISTRIK.," J. Pengemb. Energi Nukl., vol. 19, no. 2, p. 113, Apr. 2018.

[4] United Nations, "GOVERNMENT - UNITED NATIONS PARTNERSHIP FOR DEVELOPMENT FRAMEWORK (UNPDF)," 2016.

[5] A. / Esd, "Well-to-Wheels Energy Use and Greenhouse Gas Emissions Analysis of Plug-in Hybrid Electric Vehicles Energy Systems Division."

[6] X. Wu, D. Freese, A. Cabrera, and W. A. Kitch, "Electric vehicles' energy consumption measurement and estimation," Transp. Res. Part D Transp. Environ., vol. 34, pp. 52-67, Jan. 2015.

[7] F. Sutra Kamajaya and M. Muzmi Ulya, "Analisis Teknologi Charger Untuk Kendaraan ListrikReview,” J. Rekayasa Mesin, vol. 6, no. 3, pp. 163-166, 2015. 
[8] C. Dericioglu, E. Yirik, E. Unal, M. U. Cuma, B. Onur, and M. Tumay, "A REVIEW OF CHARGING TECHNOLOGIES FOR COMMERCIAL ELECTRIC VEHICLES,” Int. J. Adv. Automot. Technol. Promech Corp. Press, vol. 2, no. 1, pp. 61-70, 2018.

[9] A. Wibowo, "Evaluasi kondisi daya dukung lingkungan hidup kota Jakarta."

[10] W. Sutopo, M. Nizam, B. Rahmawatie, and F. Fahma, "A Review of Electric Vehicles Charging Standard Development: Study Case in Indonesia," Proceeding - 2018 5th Int. Conf. Electr. Veh. Technol. ICEVT 2018, pp. 152-157, 2019.

[11] P. Plötz, U. Schneider, J. Globisch, and E. Dütschke, "Who will buy electric vehicles? Identifying early adopters in Germany," Transp. Res. Part A Policy Pract., vol. 67, pp. 96-109, 2014.

[12] I. Vassileva and J. Campillo, "Adoption barriers for electric vehicles: Experiences from early adopters in Sweden," Energy, vol. 120, pp. 632-641, 2017.

[13] D. A. Giménez-Gaydou, A. S. N. Ribeiro, J. Gutiérrez, and A. P. Antunes, "Optimal location of battery electric vehicle charging stations in urban areas: A new approach," Int. J. Sustain. Transp., vol. 10, no. 5, pp. 393-405, 2016.

[14] M. Naor, E. S. Bernardes, C. T. Druehl, and Y. Shiftan, "Overcoming barriers to adoption of environmentally-friendly innovations through design and strategy," Int. J. Oper. Prod. Manag., vol. 35 , no. $1,2015$.

[15] H. Engel, R. Hensley, S. Knupfer, and S. Sahdev, "The basics of electric-vehicle charging infrastructure | McKinsey," McKinsey \& Company, 2018.

[16] A. Sheikhi, S. Bahrami, A. M. Ranjbar, and H. Oraee, "Strategic charging method for plugged in hybrid electric vehicles in smart grids; A game theoretic approach," Int. J. Electr. Power Energy Syst., vol. 53, no. 1, pp. 499-506, 2013.

[17] Tesla, "Supercharger | Tesla 香港," 2019. .

[18] L. Luo et al., "Optimal planning of electric vehicle charging stations comprising multi-types of charging facilities," Appl. Energy, vol. 226, no. June, pp. 1087-1099, 2018.

[19] HKPC, "APAS and HKAA's trial scheme on 'Smart Mobile EV Charger' - offers emergency EV charging solution anytime, anywhere - HKPC," 2018 . .

[20] P. Huang, Z. Ma, L. Xiao, and Y. Sun, "Geographic Information System-assisted optimal design of renewable powered electric vehicle charging stations in high-density cities," Appl. Energy, vol. 255, no. 2, p. 113855, 2019.

[21] MAPC, "How to Install Electric Vehicle Charging Stations - MAPC," 2018.

[22] VEIC, "Electric Vehicle Charging Station Standards," no. June, 2014.

[23] P. Sadeghi-Barzani, A. Rajabi-Ghahnavieh, and H. Kazemi-Karegar, "Optimal fast charging station placing and sizing,” Appl. Energy, vol. 125, pp. 289-299, 2014.

[24] T. Chen, K. Kockelman, and M. Khan, "Locating electric vehicle charging stations," Transp. Res. Rec., no. 2385, pp. 28-36, 2013.

[25] T. L. Sheldon, J. R. DeShazo, and R. T. Carson, "Demand for Green Refueling Infrastructure," Environ. Resour. Econ., no. December 2018, 2019.

[26] Y. Kongjeen, W. Junlakan, K. Bhumkittipich, and N. Mithulananthan, "Estimation of the Quick Charging Station for Electric Vehicles based on Location and Population Density Data," Int. J. Intell. Eng. Syst., vol. 11, no. 3, 2018.

[27] J. Wenig, M. Sodenkamp, and T. Staake, "Battery versus infrastructure: Tradeoffs between battery capacity and charging infrastructure for plug-in hybrid electric vehicles," Appl. Energy, vol. 255, no. August, p. 113787, 2019.

[28] J. Globisch, P. Plötz, E. Dütschke, and M. Wietschel, "Consumer preferences for public charging infrastructure for electric vehicles," Transp. Policy, vol. 81, no. June, pp. 54-63, 2019.

[29] ESDM, "Performance Report of Directorate General of Electricity," pp. 36-37, 2018.

[30] "Electrify America, Walmart Announce Completion of Over 120 Charging Stations at Walmart Stores Nationwide with Plans for Further Expansion." [Online]. Available: https://corporate.walmart.com/newsroom/2019/06/06/electrify-america-walmart-announcecompletion-of-over-120-charging-stations-at-walmart-stores-nationwide-with-plans-for-furtherexpansion. [Accessed: 26-Jan-2020]. 